\title{
Природный туристский потенциал Пермского края
}

\author{
В.П. Расковалов $\bowtie$ \\ Пермский государственный наџиональный исследовательский университет, Российская Федераџия \\ (614990, г. Пермь, ул. Букирева, 15)
}

\begin{abstract}
Аннотация: Обоснование. Природные условия территории определяют возможности и перспективы развития туризма. Пермский край является одним из регионов России, отличающихся многообразием природных ресурсов и условий. Пространственное разнообразие природного туристского потенциала определяет актуальность исследований в разрезе административных образований с определением различий между территориями.

Цель - оценка и географический анализ природных возможностей территории Пермского края для развития туризма.

Методика основана на применении математико-статистических методов обработки информации. Ее основа - рейтинговая оценка и типология районов Пермского края по ресурсному туристскому потенциалу с использованием факторного и кластерного анализа.

Результаты. Рейтинговая оценка районов Пермского края позволила выявить территории с разными ресурсными возможностями для развития туризма. Она определяет местоположение каждого района и долю в общем потенциале края. В основу анализа положена типология районов края, которая позволяет объединить районы в группы (типы) со схожими возможностями для развития туризма.

Bblводыl: В результате исследования были ранжированы все районы Пермского края по величине природного туристского потенциала и выделено 4 типа районов с разным его уровнем. Наибольшие показатели оказались характерны для северных и северо-восточных районов. Также значительным потенциалом обладает ряд центральных, западных и южных территорий региона.
\end{abstract}

Ключевые слова: туризм, природный потенциал, Пермский край, район, рейтинговая оценка, типология.

Для цитирования: Расковалов В. П. Природный туристский потенциал Пермского края // Вестник Воронежского государственного университета. Серия: География. Геоэкология, 2020, № 2, с. 22-28. DOI: https://doi.org/10.17308/geo.2020.2/2881

\section{ВВЕДЕНИЕ}

Роль природных факторов как предпосылки для организации и развития туристской деятельности всегда считалась основополагающей и определяющей специфику и специализацию туризма того или иного района. Все формы туризма, так или иначе, приурочены к конкретной территории, на которой условия природной среды являются первичными, и именно природные характеристики района в той или иной степени благоприятствуют или препятствуют организации и развитию туризма. В связи с этим проблема выявления и оценки природных условий территории для организации туризма всегда была актуальной и продолжает ею оставаться и в настоящее время.
Пространственная неоднородность природного потенциала приводит к необходимости обнаружения местностей с неодинаковыми условиями для развития туризма и определяет актуальность оценочных работ в территориальном разрезе.

Для оценки и анализа ресурсной основы туризма предложено немало подходов и методов, представленных в различных научных источниках. Ряд работ освещает компонентный подход, подразумевающий изучение и оценивание одного или нескольких компонентов природных геосистем - климат [1, 2, 3], рельеф [6, 10, 12, 19], водные ресурсы [16], растительные сообщества [9]. Тематике ландшафтной туристской оценки природных условий посвящены современные исследования $[1,13]$.

(С Расковалов В.П., 2020

E-mail: v.p.raskovalov@gmail.com

Контент доступен под лицензией Creative Commons Attribution 4.0 License. 
Рейтинговая оценка районов Пермского края по природному потенциалу развития туризма

[Table. Rating of the Perm Krai districts by natural potential of tourism development]

\begin{tabular}{|l|c|c|}
\hline \multicolumn{1}{|c|}{ Район / } & $\begin{array}{c}\text { Доля, \% / } \\
\text { Percentage }\end{array}$ & $\begin{array}{c}\text { Paнг / } \\
\text { Rank }\end{array}$ \\
\hline Александровский & 3,62 & 6 \\
\hline Бардымский & 1,97 & 22 \\
\hline Березовский & 1,72 & 29 \\
\hline Большесосновский & 1,74 & 28 \\
\hline Верещагинский & 0,99 & 39 \\
\hline Гайнский & 4,59 & 3 \\
\hline Горнозаводский & 3,99 & 5 \\
\hline Гремячинский & 3,44 & 7 \\
\hline Губахинский & 3,37 & 10 \\
\hline Добрянский & 3,38 & 9 \\
\hline Еловский & 1,88 & 25 \\
\hline Ильинский & 0,22 & 42 \\
\hline Карагайский & 1,18 & 36 \\
\hline Кизеловский & 3,4 & 8 \\
\hline Кишертский & 2,06 & 20 \\
\hline Косинский & 2,84 & 12 \\
\hline Кочевский & 1,94 & 23 \\
\hline Красновишерский & 4,85 & 2 \\
\hline Краснокамский & 1,6 & 30 \\
\hline Кудымкарский & 1,88 & 26 \\
\hline Куединский & 2,35 & 17 \\
\hline
\end{tabular}

\begin{tabular}{|l|c|c|}
\hline \multicolumn{1}{|c|}{$\begin{array}{c}\text { Район / } \\
\text { District }\end{array}$} & $\begin{array}{c}\text { Доля, \% / } \\
\text { Percentage }\end{array}$ & $\begin{array}{c}\text { Paнг / } \\
\text { Rank }\end{array}$ \\
\hline Кунгурский & 2,81 & 13 \\
\hline Льсьвенский & 2,92 & 11 \\
\hline Нытвенский & 1,29 & 34 \\
\hline Октябрьский & 2,47 & 15 \\
\hline Ординский & 1,14 & 37 \\
\hline Осинский & 1,39 & 32 \\
\hline Оханский & 1,93 & 24 \\
\hline Очерский & 1,24 & 35 \\
\hline Пермский & 2,24 & 18 \\
\hline Сивинский & 0,9 & 40 \\
\hline Соликамский & 4,04 & 4 \\
\hline Суксунский & 1,37 & 33 \\
\hline Уинский & 0,69 & 41 \\
\hline Усольский & 2,56 & 14 \\
\hline Чайковский & 1,88 & 27 \\
\hline Частинский & 1,48 & 31 \\
\hline Чердынский & 8,95 & 1 \\
\hline Чернушинский & 2,02 & 21 \\
\hline Чусовской & 2,45 & 16 \\
\hline Юрлинский & 2,1 & 19 \\
\hline Юсьвинский & 1,13 & 38 \\
\hline
\end{tabular}

Помимо отечественных исследований существуют зарубежные работы, посвященные изучению и оценке природных туристских возможностей различных территорий $[14,22]$.

В самое последнее время отмечается интерес к проведению оценки комплексного ресурсного потенциала туризма, основной составляющей которого являются природные условия $[4,8,15,17,18,21]$.

Оценка отдельных природных ресурсов и комплексного туристского потенциала Пермского края отражена в исследованиях $[5,7,20]$.

\section{МЕТОДИКА ИССЛЕДОВАНИЯ}

Основа методики - оценка и территориальный анализ природных ресурсных возможностей Пермского края для организации и развития туризма. При этом учитываются не только факторы, благоприятствующие развитию туристской деятельности, но и ограничивающие. Цель исследования рейтинговая оценка и типология административно-территориальных образований региона. Рейтинговая оценка позволяет расположить районы в порядке их приоритетности по качеству природ-

ных условий, а типология - объединить территории в группы с похожим потенциалом. Для проведения наиболее точного сравнительного исследования края используются методы математической статистики - факторный и кластерный анализ. Операционно-территориальная единица (OTE) административные районы Пермского края. Каждый район описывается системой показателей и сравнивается с другими ОТЕ.

Совместное применение показателей, представленных в разных измерениях, требует преобразования их количественных характеристик в безразмерную величину. Поэтому сначала осуществляется нормирование первичных данных. Кроме того, принимается во внимание значимость каждого фактора в суммарном потенциале, для чего используется факторный анализ. Он позволяет определить величину весовых коэффициентов каждого показателя. Затем, показатели, наделенные определенным весом, складываются в оценочную сумму двух блоков - благоприятствующих и ограничивающих туристскую деятельность. В 


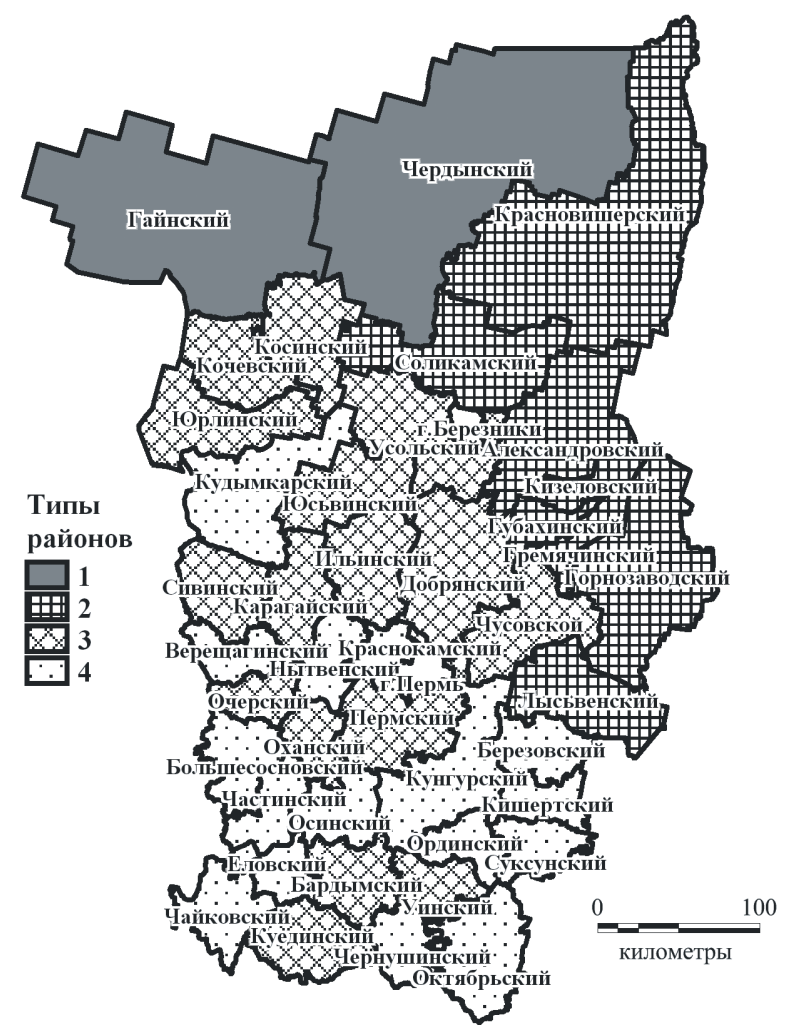

Puc. Природный потенциал районов Пермского края для развития туризма:

1 - наивысший; 2 - высокий; 3 - средний; 4 - низкий

[Fig. Natural potential of the Perm Krai districts for tourism development:

1 - the highest; 2 - high; 3 - medium; 4 - low]

результате, интегральный показатель природного туристского потенциала каждой ОТЕ рассчитывается по формуле:

$$
\text { ИП }=\left(k_{1} c_{1}+\ldots+k_{n} c_{n}\right)-\left(r_{1} p_{1}+\ldots+r_{n} p_{n}\right),
$$

где ИП - интегральный показатель; $k_{1} . . k_{n}$ - весовые коэффициенты показателей благоприятствующих факторов; $c_{1} \ldots c_{n}-$ нормированные значения показателей благоприятствующих факторов; $r_{1} \ldots r_{n}$ - весовые коэффициенты показателей ограничивающих факторов; $p_{1} \ldots p_{n}$ - нормированные значения показателей ограничивающих факторов; $n$ число суммируемых показателей.

Следующий этап исследования - типология ОТЕ по природному туристскому потенциалу, в основе которой лежит кластерный анализ. Он классифицирует совокупности схожих между собой территорий по комплексу показателей. Кластерный анализ разделяет ОТЕ на группы - кластеры, принимающие во внимание все признаки сразу. Итогом стало объединение ОТЕ в группы районов, а суммирование средних значений показателей в кластере для каждой группы определяет качествен- ную характеристику, показывающую уровень потенциала. Территории, имеющие максимальные природные возможности были включены в первый тип, а районы с наименьшим потенциалом - в тип самого меньшего ранга.

\section{РЕЗУЛЬТАТЫ ИССЛЕДОВАНИЯ И ОБСУЖДЕНИЕ}

Оценка природного потенциала состоит из показателей контрастности рельефа, разнообразия и эстетической привлекательности ландшафтов, наличия водных объектов, лесистости и иных лесных ресурсов для сбора дикоросов (грибов, ягод и лекарственных растений), обеспеченности охотничьими ресурсами, а также наличия ООПТ. Ограничивающие факторы представлены показателями, учитывающими эколого-географическую обстановку и особенности распространения природно-очаговых заболеваний в Пермском крае.

Подводя итог оценки (таблица), видно, что наибольший ранг имеют Чердынский, Красновишерский, Гайнский, Соликамский, Горнозаводский районы, а наименьший - Юсьвинский, Верещагинский, Сивинский, Уинский, Ильинский районы.

Типология выявила 4 типа районов (рис.). I тип - 2 района (Чердынский и Гаинский) с максимальным природным потенциалом. Они расположены на северной окраине региона. Для них характерны очень высокие значения показателей гидрологической составляющей природных условий. На этих территориях насчитывается 65 крупных рек. Среди них одни из крупнейших и многоводных рек края - Кама, Вишера, Колва, Весляна. Районы лидирует и по количеству других водных объектов, их выявлено 105. Среди них крупнейшие в крае озера - Чусовское, Большой Кумикуш, Новожилово, Адово. Данная территория характеризуется очень высоким потенциалом запасов грибов и ягод, а также условий для охоты. Чердынский и Гайнский районы отличаются очень высокой контрастностю ландшафтов и большим разнообразием ООПТ. Чердынский район обладает максимальным по сравнению с другими районами количеством охраняемых природных территорий -54 . Кроме того, оба района достаточно лесистые (Гайнский - 89,32\%, Чердынский - 86,12\% от площади территории района). Территория Чердынского района отличается самой благоприятной экологической и природно-эпидемиологической ситуацией. В целом влияние ограничивающих факторов природной среды минимально. Из двух районов максимальный туристский потенциал имеет Чердынский район. 
II mun - 8 районов с высокими возможностями. Этим районам присущи высокие значения показателей контрастности рельефа, и соответственно, благоприятные для организации туризма орографические условия. В Гремячинском и Горнозаводском районах самые высокие в крае крутизна склонов и густота долинного расчленения. Территории в этом типе расположены в северовосточных и восточных частях края, где наиболее выражена расчлененность рельефа, представленного среднегорьем Северного Урала и низкогорьем Среднего Урала. Здесь находятся высочайшие точки Прикамья - гора Тулымский Камень и гора Ишерим. Максимальную в крае лесистость имеют Горнозаводский $(92,65 \%)$, Александровский $(91,82 \%)$, Гремячинский $(90,92 \%)$, Кизеловский $(89,32 \%)$ районы. Здесь в целом высокая обеспеченность ООПТ. В Красновишерском районе 23 охраняемые территории, в Соликамском - 19. Красновишерский, Гремячинский, Горнозаводский, Кизеловский и Александровский районы имеют самую высокую в крае пейзажную привлекательность. Несмотря на то, что данная группа районов имеет в общем среднюю обеспеченность гидрологическими ресурсами, но Губахинский район занимает лидирующую позицию среди всех районов края по площади водных объектов $(31,49$ на тыс. кв. км). Причина - Широковское водохранилище на р. Косьве. Высокому туристскому потенциалу данной территории способствуют благоприятные ограничивающие условия природой среды.

III mun - 16 районов, обладающих средними природными предпосылками для туризма. Это территории, расположенные в северной, северо-западной и центральной частях региона, за исключением трех районов в его южной половине (Куединский, Бардымский, Уинский). Эта группа районов отличается достаточно густотой речной сетью (Косинский район - 12 крупных рек, Кочевский - 11, Усольский - 11, Чусовской - 10) и большим количеством иных водных объектов (Косинский - 10 , Пермский - 10). По этой территории протекает главная водная артерия региона - река Кама с ее притоками (Коса, Иньва, Обва, Чусовая, Тулва). Ряд районов отличается высокой площадью охотничьих угодий (Усольский - 96,57\%, Сивинский - 95,12\%, Косинский - 94,66\% от площади территории района). Но несмотря на имеющийся положительный потенциал, территории районов в целом имеют неблагоприятные показатели по экологическим и природно-эпидемиологическим условиям.
$I V$ mun - 16 районов, находящиеся в центральной и южной частях края. К этому типу относится Кудымкарский район, расположенный на северозападной окраине. Все районы обладают природным потенциалом ниже среднего. Типу присущи сравнительно высокие ресурсные возможности для сбора дикоросов - грибов, ягод и лекарственных растений. Также районы отличаются контрастностью рельефа и пейзажным разнообразием. Остальные показатели имеют в основном более низкие значения по сравнению с другими типами районов.

\section{ЗАКЛЮЧЕНИЕ}

Методика исследования ориентирована на рейтинговую оценку районов Пермского края по величине природного ресурсного потенциала с учетом ограничивающих факторов развития туризма. Примененный метод позволил определить процентное отношение каждого района к суммарному потенциалу края, и соответственно его местоположение относительно других территорий. Типологический подход объединяет районы в группы, имеющие общие характеристики и сходные туристские предпосылки.

Результаты рейтинговой оценки и типологии природного туристского потенциала позволили выделить районы с наиболее предпочтительными возможностями развития туризма. Определены территории, где развитие туризма в той или иной степени может сдерживаться неблагоприятной эколого-географической и природно-эпидемиологической обстановкой.

\section{СПИСОК ЛИТЕРАТУРЫ}

1. Асташин А. Е., Ершова К. В., Самойлов А. В., Никитина О.А. Ландшафтная структура как основа туристско-рекреационной оценки территории (на примере Городецкого района Нижегородской области) // Междунар. науч.-исслед. журнал, 2016, № 1(43), ч. 2, с. 111115. DOI: $10.18454 /$ IRJ.2016.43.112.

2. Божилина Е. А, Белова Д. А., Сорокина В.Н. Климатические карты для рекреации и туризма // Вестник Моск. ун-та. Сер. 5. География, 2008, № 3, с. 19-23.

3. Гармс Е. О., Сухова М. Г., Ромашова Т. В. Рекреационная оценка биоклимата трансграничной территории Алтая // Вестник Томского гос. ун-та, 2013, № 370, c. $148-155$.

4. Гудковских М. В. Методика комплексной оценки туристско-рекреационного потенциала // Геогр. вестник, 2017, № 1(40), с. 102-116.

5. Девяткова С. Б. Использование ресурсного потенциала природно-территориальных комплексов для целей рекреации // География и туризм: сб. науч. тр. Пермь, Перм. ун-т, 2006, вып. 2. С. 41-54. 
6. Егорина А. В., Логиновская А. Н. Рельеф как фактор рекреационной деятельности (на примере Восточного Казахстана) // Наука и туризм: стратегии взаимодействия, 2014, № 3, с. 47-50.

7. Зырянов А. И., Мышлявцева С. Э., Вопилова Е. С., Расковалов В. П., Щепеткова И. О. Пространственное развитие туризма в Пермском крае // Труды III междунар. науч.-практ. конф.: «Туризм и рекреация: фундаментальные и прикладные исследования». Москва, АНО «Диалог культур», 2008, с. 447-454.

8. Конышев Е.В. Социально-географические особенности развития туризма в Кировской области. Автореф. дис. ... канд. геогр. наук. Пермь, 2005. 19 с.

9. Королева И. С., Епринцев С. А. Функциональная модель рекреационной оценки лесных территорий с использованием ГИС-технологий // Вестник Воронежского государственного университета. Серия География. Геоэкология, 2013, № 1, с. 99-101.

10. Лось М. А. Оценка рельефа Тюменско-Тобольского туристско-рекреационного каркаса в целях развития туризма // Геогр. вестник, 2017, № 4(43), с. 161-169.

11. Луковская И. А., Севастьянов В. В., Сухова М.Г. Климато-рекреационные ресурсы Кузнецкого Алатау // Вестник Томского гос. университета, 2012, № 354, c. 205-209.

12. Макаренко Е.П. Рекреационно-экологическая оценка рельефа как ведущего фактора развития туризма (на примере Томского района) // Вестник Кемеровского гос. университета, 2015, № 2-7, с. 115-120.

13. Марков Д.С. Комплексная оценка туристскорекреационного потенциала ландшафтов // Вестник БГУ, 2011, № 4, с. 203-207.

14. Мосько Т. В. Комплексная оценка туристско-рекреационных ресурсов Гомельской области // Инновационная экономика: перспективы развития и совершенствования, 2016, № 1(11), с. 177-188.

15. Нестеров Ю. А., Рощевкин Р. С., Прохорова О. В. Оценка потенциала развития экологического туризма на территории Воронежской области // Вестник Воронежского государственного университета. Серия География. Геоэкология, 2013, № 1, с. 163-171.

16. Проскурина Н. В., Щербинина С. В. Водные (гидрологические) ресурсы как фактор туристско-рекреационного освоения Липецкой области // Вестник Воронежского государственного университета. Серия География. Геоэкология, 2015, № 4, с. 24-27.

17. Рязанцев А. С., Худякова Т. М. Территориальная структура туристско-рекреационного потенциала Воронежской области // Вестник Воронежского государственного университета. Серия География. Геоэкология, 2019, №3, с. 86-91.

18. Саранча М.А. Методологический проблемы интегральной оценки туристско-рекреационного потенциала территории // Вестник УдмГУ. Биология. Науки о Земле, 2011, вып. 1, с. 118-127.

19. Семочкина С. С. Оценка ландшафтно-рекреационного потенциала равнинной территории левобережья Оби по геоморфологическим показателям // Известия АлтГУ, 2011, № 3-1(71), с. 74-75.

20. Худеньких Ю.А. Пермский туризм: территориальная организация и региональное развитие. Пермь, Перм. ун-т, 2006. 189 с.

21. Худякова Т.М., Рязанцев А.С. Формирование территориальных туристско-рекреационных систем Воронежской области // Вестник Воронежского государственного университета. Серия География. Геоэкология, 2015, № 4, с. 36-42.

22. Vystoupil J., Sauer M., Repik O. Quantitative analysis of tourism potential in the Czech Republic // Acta Univ. Agric. Silvic. Mendelianae Brunensis, 2017, v. 65, no. 3, pp. 1085-1098. DOI: 10.11118/actaun201765031085.

Конфликт интересов: Автор декларирует отсутствие явных и потенциальных конфликтов интересов, связанных с публикацией настоящей статьи.

Поступила в редакциию 10.06.2019

Принята к публикации 02.06.2020

UDC 338.483(470.53/531)

ISSN 1609-0683

DOI: https://doi.org/10.17308/geo.2020.2/2881

\title{
Natural Tourism Potential of the Permsky Krai
}

\author{
V. P. Raskovalov $\bowtie$ \\ Perm State National Research University, Russian Federation \\ (15, Bukireva St., Perm, 614990)
}

Abstract: Rationale: The natural conditions of territory determine the opportunities and prospects for tourism development. The Permsky Krai is one of the regions of Russia, charactering by a variety of natural

(C) Raskovalov V. P., 2020

\ E-mail: v.p.raskovalov@gmail.com

The content is available under Creative Commons Attribution 4.0 License. 
resources and conditions. A spatial variety of natural tourism potential determines relevance of researches in context of administrative units with definition of distinctions between territories.

Purpose: The purpose of the research is the assessment and geographical analysis of natural opportunities of the Permsky Krai for tourism development.

Methodology: Methods based on application of mathematical and statistical techniques of information processing. Its basis is a rating assessment and typology of the Permsky Krai districts according to resource tourism potential using factor and cluster analysis.

Results: The rating assessment of the Permsky Krai districts gave identify territories with different resource capabilities for tourism development. It defines location of each district and its percentage in the total potential of region. The analysis is based on typology of the Krai districts, which allows combining districts into groups (types) with similar opportunities for tourism development.

Conclusions: As a result of the research, all districts of the Permsky Krai were ranked in terms of natural tourism potential and 4 types of districts of the region with different levels were identified. The highest indicators were characteristic of the northern and northeastern districts. Some central, western and southern areas of the region have a significant tourism potential.

Key words: tourism, natural potential, the Permsky Krai, district, rating assessment, typology.

For citation: Raskovalov V. P. Natural Tourism Potential of the Permsky Krai. Vestnik Voronezskogo gosudarstvennogo universiteta. Seria Geografiya. Geoekologiya, 2020, No. 2, pp. 22-28. (In Russ.) DOI: https://doi.org/10.17308/geo.2020.2/2881

\section{REFERENCES}

1. Astashin A. E., Ershova K. V., Samoylov A. V., Nikitina O. A. Landshaftnaya struktura kak osnova turistskorekreatsionnoy otsenki territorii (na primere Gorodetskogo rayona Nizhegorodskoy oblasti) [Landscape structure as the basis of the tourist-recreational assessment of the territory (on the example of the Gorodetsky district of the Nizhny Novgorod region)]. Mezhdunar. nauch.-issled. Zhurnal, 2016, no. 1(43), pt. 2, pp. 111-115. DOI: 10.18454/ IRJ.2016.43.112. (In Russ.)

2. Bozhilina E. A, Belova D. A., Sorokina V. N. Klimaticheskie karty dlya rekreatsii i turizma [Climate maps for recreation and tourism]. Vestnik Mosk. un-ta. Ser. 5. Geografiya, 2008, no. 3, pp. 19-23. (In Russ.)

3. Garms E. O., Sukhova M.G., Romashova T. V. Rekreatsionnaya otsenka bioklimata transgranichnoy territorii Altaya [Recreational assessment of the bioclimat of the transboundary territory of Altai]. Vestnik Tomskogo gos. un-ta, 2013, no. 370, pp. 148-155. (In Russ.)

4. Gudkovskikh M. V. Metodika kompleksnoy otsenki turistsko-rekreatsionnogo potentsiala [Methodology for a comprehensive assessment of tourist and recreational potential]. Geogr. vestnik, 2017, no. 1(40), pp. 102-116. (In Russ.)

5. Devyatkova S. B. Ispol'zovanie resursnogo potentsiala prirodno-territorial'nykh kompleksov dlya tseley rekreatsii [Using the resource potential of natural-territorial complexes for recreation purposes]. Geografiya i turizm: sb. nauch. tr. [Collected articles "Geography and tourism"]. Perm, Perm Univ. Publ., 2006, iss. 2. Pp. 41-54. (In Russ.)

6. Egorina A. V., Loginovskaya A. N. Rel'ef kak faktor rekreatsionnoy deyatel'nosti (na primere Vostochnogo Kazakhstana) [Relief as a factor of recreational activity (on the example of East Kazakhstan)]. Nauka i turizm: strategii vzaimodeystviya, 2014, no. 3, pp. 47-50. (In Russ.)

7. Zyryanov A. I., Myshlyavtseva S. E., Vopilova E. S., Raskovalov V.P., Shchepetkova I. O. Prostranstvennoe razvitie turizma $v$ Permskom krae [Spatial development of tour- ism in the Perm region]. Turizm i rekreatsiya: fundamental'nye i prikladnye issledovaniya: tr. III mezhdunar. nauch.-prakt. konf. [Proc. of the 3th Int. Sci.-Pract. Conf. "Tourism and recreation: fundamental and applied research"]. Moscow, Publ. ANO "Dialog kul'tur", 2008, pp. 447-454. (In Russ.)

8. Konyshev E. V. Sotsial'no-geograficheskie osobennosti razvitiya turizma $v$ Kirovskoy oblasti [Socio-geographical features of the development of tourism in the Kirov region]. Avtoref. dis. ... kand. geogr. nauk [Abstract of Cand. Sci. (Geogr.) Diss.]. Perm, 2005. 19 p. (In Russ.)

9. Koroleva I. S., Eprintsev S. A. Funktsional'naya model' rekreatsionnoy otsenki lesnykh territoriy s ispol'zovaniem GIS-tekhnologiy [Functional model of recreational assessment of forest areas using GIS technologies]. Vestnik Voronezskogo gosudarstvennogo universiteta. Seria Geografia. Geoekologia, 2013, no. 1, pp. 99-101. (In Russ.)

10. Los' M. A. Otsenka rel'efa Tyumensko-Tobol'skogo turistsko-rekreatsionnogo karkasa $\mathrm{v}$ tselyakh razvitiya turizma [Relief assessment of the Tyumen-Tobolsk tourist and recreational framework for the development of tourism]. Geogr. Vestnik, 2017, no. 4(43), pp. 161-169. (In Russ.)

11. Lukovskaya I. A., Sevast'yanov V. V., Sukhova M. G. Klimato-rekreatsionnye resursy Kuznetskogo Alatau [Climatic and recreational resources of the Kuznetsk Alatau]. Vestnik Tom. gos. un-ta, 2012, no. 354, pp. 205-209. (In Russ.)

12. Makarenko E.P. Rekreatsionno-ekologicheskaya otsenka rel'efa kak vedushchego faktora razvitiya turizma (na primere Tomskogo rayona) [Recreational-ecological assessment of the relief as a leading factor in the development of tourism (on the example of the Tomsk district)]. Vestnik Kemerovskogo GU, 2015, v. 7, no. 2(62), pp. 115-120.

13. Markov D.S. Kompleksnaya otsenka turistskorekreatsionnogo potentsiala landshaftov [Comprehensive assessment of the tourist and recreational potential of landscapes]. Vestnik BGU, 2011, no. 4, pp. 203-207. (In Russ.) 
14. Mos'ko T. V. Kompleksnaya otsenka turistskorekreatsionnykh resursov Gomel'skoy oblasti [Comprehensive assessment of tourist and recreational resources of the Gomel region]. Innovatsionnaya ekonomika: perspektivy razvitiya i sovershenstvovaniya, 2016, no. 1(11), pp 177188. (In Russ.)

15. Nesterov Yu. A., Roshchevkin R.S., Prokhorova O. V. Otsenka potentsiala razvitiya ekologicheskogo turizma na territorii Voronezhskoy oblasti [Assessment of the potential for the development of ecotourism in the Voronezh region]. Vestnik Voronezskogo gosudarstvennogo universiteta. Seria Geografia. Geoekologia, 2013, no. 1, pp. 163-171. (In Russ.)

16. Proskurina N. V., Shcherbinina S. V. Vodnye (gidrologicheskie) resursy kak faktor turistsko-rekreatsionnogo osvoeniya Lipetskoy oblasti [Water (hydrological) resources as a factor of tourist and recreational development of the Lipetsk region]. Vestnik Voronezskogo gosudarstvennogo universiteta. Seria Geografia. Geoekologia, 2015, no. 4, pp. 24-27. (In Russ.)

17. Ryazantsev A.S., Khudyakova T.M. Territorial'naya struktura turistsko-rekreatsionnogo potentsiala Voronezhskoy oblasti [The territorial structure of the tourist and recreational potential of the Voronezh region]. Vestnik Voronezskogo gosudarstvennogo universiteta. Seria Geografia. Geoekologia, 2019, no. 3, pp. 86-91. (In Russ.)

18. Sarancha M. A. Metodologicheskiy problemy integral'noy otsenki turistsko-rekreatsionnogo potentsiala

Расковалов Вячеслав Павлович

кандидат географических наук кафедры туризма Пермского государственного национального исследовательского университета, г. Пермь, ORCID: https://orcid.org/ 0000-0003-1013-3301, e-mail: v.p.raskovalov@ gmail.com territorii [Methodological problems of integrated assessment of tourist and recreational potential of the territory]. Vestnik Udmurtskogo GU. Biologiya. Nauki o Zemle, 2011, iss. 1, pp. 118-127. (In Russ.)

19. Semochkina S. S. Otsenka landshaftno-rekreatsionnogo potentsiala ravninnoy territorii levoberezh'ya Obi po geomorfologicheskim pokazatelyam [Assessment of landscape and recreational potential of the plain territory of the left bank of the $\mathrm{Ob}$ according to geomorphological indicators]. Izvestiya AltGU, 2011, no. 3-1(71), pp. 74-75. (In Russ.)

20. Khuden'kikh Yu.A. Permskiy turizm: territorial'naya organizatsiya i regional'noe razvitie [Perm tourism: territorial organization and regional development]. Perm, Perm University Publ., 2006. 189 p. (In Russ.)

21. Khudyakova T. M., Ryazantsev A. S. Formirovanie territorial'nykh turistsko-rekreatsionnykh sistem Voronezhskoy oblasti [Formation of territorial tourist and recreational systems of the Voronezh region]. Vestnik Voronezskogo gosudarstvennogo universiteta. Seria Geografia. Geoekologia, 2015, no. 4, pp. 36-42. (In Russ.)

22. Vystoupil J., Sauer M., Repik O. Quantitative analysis of tourism potential in the Czech Republic. Acta Univ. Agric. Silvic. Mendelianae Brunensis, 2017, v. 65, no. 3, pp. 1085-1098. DOI: 10.11118/actaun201765031085.

Conflict of interests: The author declares no information of obvious and potential conflicts of interest related to the publication of this article.

Received: 10.06 .2019

Accepted: 02.06.2020

Vyacheslav P. Raskovalov

Cand. Sci. (Geogr.), Assoc. Prof. of the Tourism Department, Perm State National Research University, Perm, ORCID: https://orcid.org/0000-0003-1013-3301, e-mail: v.p.raskovalov@gmail.com 